\title{
The Variation of Excess Base with Depth in the English Channel with reference to the Seasonal Consumption of Calcium by Plankton.
}

\author{
By \\ I. H. N. Cooper, Ph.D., A.I.C., \\ Assistant Chemist at the Plymouth Laboratory.
}

Since excess base or titration alkalinity increases with increasing chlorinity, the ratio, $\frac{\text { excess base }}{\text { chlorinity }}$, termed by Wattenberg the "specific alkalinity," is the most suitable quantity to consider when determining whether or not excess base varies with depth or from time to time. Wattenberg (5) has shown that a marked increase occurs in the great ocean depths immediately above the bottom. There is at present no evidence, other than that found by the writer (2), for the English Channel in the summer of 1931, to suggest any variation of excess base in shoal water on the continental shelf and away from the influence of large rivers such as appear to affect the Heligoland Bight (Zorell, 6). The variation found in 1931 was small and of the order of the experimental error of any one pair of observations. To overcome this difficulty, statistical methods were applied to the grouped results obtained from similar depths during the summer and early autumn of 1931 . The differences found between the specific alkalinities of the surface and bottom waters were several times the standard errors. The conclusions, however, were open to criticism in that the experimental results were not designed for statistical treatment.

In the summer of 1933 the problem was attacked somewhat differently. From each sample, contained in a number of $170 \mathrm{ml}$. standard sample bottles, about six to fifteen sub-samples, each $100 \mathrm{ml}$., were analysed for excess base by the method of Wattenberg (4) which had been used in 1931. It is generally recognised that in making a series of consecutive determinations on one quantity, the later results may not be independent of the earlier. Particularly in reading a burette there is a tendency to "adjust" the value read in accordance with the knowledge already gained on the sample. To overcome this, analyses of sub-samples of different samples were carried out in a haphazard sequence in flasks marked by a reference letter only, so that the origin of the sub-samples 
was at the time unknown. Again, in some analyses the volume of the subsample was increased by $1 \mathrm{ml}$. in order slightly to displace the titration.

The standardisation of the $\mathrm{N} / 20$ baryta in terms of $10 \mathrm{ml}$. of $\mathrm{N} / 20$ hydrochloric acid was carried out in quadruplicate and the mean taken as the true value. From this each titration of sea-water was subtracted in order to get the " baryta equivalents" of the excess base. These were then corrected for the error at the temperature of the laboratory of the two $100 \mathrm{ml}$. pipettes used for measuring the water. On each occasion the pipettes were calibrated by weighing the distilled water delivered under standard conditions. The distilled water had been allowed to attain the temperature of the laboratory and its volume was calculated from its temperature and weight. In any one working day the temperature of the laboratory did not vary by more than $2^{\circ} \mathrm{C}$.

For each set of sub-samples, the mean baryta equivalent was found and the sum of the squares of the deviations from the mean gave the variance, $\Sigma \mathrm{d}_{\mathrm{n}}{ }^{2}$. The standard error for the sample was then derived from the formula :-

$$
\rho_{\mathrm{A}}=\sqrt{\frac{\sum \mathrm{d}_{\mathrm{n}}^{2}}{\mathrm{n}(\mathrm{n}-1)}}
$$

It must be admitted that owing to their small number the baryta equivalents of the sub-samples do not fall on a typical population curve. The means and standard errors were then multiplied by the baryta normality factor to give the excess base in milliequivalents per litre.

In earlier work the ratio considered for specific alkalinity, $\Lambda$, was :-

$$
\Lambda_{\mathrm{v}}=\frac{\text { excess base in milliequivalents per litre }}{\text { chlorinity in grams per kilogram }}=\frac{A_{\mathrm{v}}}{\mathrm{Cl}}
$$

Elsewhere the writer (3) has discussed the advisability of replacing this volume/weight ratio by the weight/weight ratio :-

$$
\Lambda_{\mathrm{w}}=\frac{\text { excess base in milliequivalents per kilogram }}{\text { chlorinity in grams per kilogram }}=\frac{\mathrm{A}_{\mathrm{w}}}{\mathrm{Cl}}
$$

i.e. a ratio which varies with temperature may be replaced by one which is invariant. The excess base has therefore been converted to milliequivalents per kilogram by dividing by $\sigma_{t}$, the density found from the chlorinity and the temperature of the laboratory.

Since the determinations of chlorinity are relatively considerably more accurate than those of excess base, fewer sub-samples were called for. Indeed, no great error would be introduced by ignoring the standard error of the chlorinity and relying on one determination. The specific alkalinity has then to be found from the expression :-

$$
\Lambda \pm \rho_{\mathrm{A}}=\frac{\mathrm{A} \pm \rho_{\mathrm{A}}}{\mathrm{Cl} \pm \rho_{\mathrm{Cl}}}
$$


TABLE I.

\begin{tabular}{|c|c|c|c|c|c|c|c|c|c|c|c|}
\hline \multirow{2}{*}{$\begin{array}{c}\text { Date } \\
1933 \\
\text { and temp. } \\
\text { of Lab. }\end{array}$} & \multirow[b]{2}{*}{ Station } & \multirow[b]{2}{*}{$\begin{array}{l}\text { Depth } \\
\text { metres }\end{array}$} & \multicolumn{2}{|c|}{$\mathrm{B} \times \mathrm{CBS} \mathrm{S}$} & \multicolumn{2}{|l|}{ B A S E } & \multicolumn{3}{|c|}{$C$ H I ORINI T Y } & \multicolumn{2}{|c|}{ SPECIFIC ALKAZINITY } \\
\hline & & & \begin{tabular}{|l|} 
No, of \\
sub-samples \\
analyoed
\end{tabular} & $\begin{array}{l}A_{v} \text { (vol/wt) } \\
\text { milli-equiv } \\
\text { per litro }\end{array}$ & $\begin{array}{l}A_{w} \\
\text { milli-equiv } \\
\text { per kg. }\end{array}$ & \begin{tabular}{c|}
$(w t / w t)$ \\
Standard \\
Error \\
$\rho A_{w}$ \\
\end{tabular} & $\begin{array}{c}\text { No. of } \\
\text { sub-sampl es } \\
\text { analysed }\end{array}$ & $\begin{array}{l}\mathrm{Cl} \\
\% 0\end{array}$ & $\begin{array}{l}\text { Standard } \\
\text { firror } \\
\rho_{C l}\end{array}$ & $\Lambda_{m} \times 10^{4}$ & $\begin{array}{l}\text { Standard } \\
\text { Frror } \\
\Lambda_{\mathbb{w}} \times 30^{4}\end{array}$ \\
\hline \multirow{6}{*}{$\begin{array}{l}18 / 7 \\
24^{\circ} \mathrm{C}\end{array}$} & \multirow[t]{2}{*}{ I 4} & 0 & 7 & 2.3692 & 2.3146 & 0.00207 & 6 & 19.323 & 0.0027 & 2197.8 & 1.19 \\
\hline & & 50 & 6 & 2.3850 & 2.3299 & 0.00277 & 6 & 19.341 & 0.0038 & 1204.7 & 1.45 \\
\hline & \multirow[t]{4}{*}{26} & 0 & 12 & 2.3590 & 2.3046 & 0.00178 & 4 & 19.314 & 0.0013 & 1193.3 & 0.93 \\
\hline & & 5 & 4 & 2.3623 & 2.3078 & 0.00349 & 3 & 19.322 & 0.0036 & 1194.4 & 1.82 \\
\hline & & 25 & 13 & 2.3724 & 2.3176 & 0.00148 & 5 & 19.350 & 0.0020 & 219.7 .7 & 0.78 \\
\hline & & 68 & 15 & 2.3814 & 2.3263 & 0.00242 & 4 & 19.359 & 0.0038 & 1201.7 & 1.27 \\
\hline \multirow{6}{*}{$\begin{array}{c}10 / 8 \\
22.5^{\circ} \mathrm{C} \\
19 / 9 \\
18^{\circ} \mathrm{C}\end{array}$} & \multirow[t]{2}{*}{$\mathrm{ES}_{3}$} & 0 & 5 & 2.3604 & 2.3051 & 0.00132 & 1 & 19.36 & - & 1190.5 & 0.70 \\
\hline & & 69 & 5 & 2.3690 & 2.3134 & 0.00498 & 1 & 19.33 & - & 1196.8 & 2.60 \\
\hline & \multirow[t]{2}{*}{ I 4} & 0 & 6 & 2.3582 & 2.3000 & 0.00107 & 4 & 19.379 & 0.0013 & 1186.8 & 0.56 \\
\hline & & 50 & 9 & 2.3740 & 2.3153 & 0.00235 & 4 & 19.390 & 0.0029 & 1194.1 & 1.22 \\
\hline & \multirow[t]{2}{*}{ B 1 . } & 0 & 8 & 2.3617 & 2.3027 & 0.00286 & 3 & 19.434 & 0.0021 & 1184.9 & 1.47 \\
\hline & & 69 & 10 & 2.3768 & 2.3281 & 0.00136 & 3 & 19.417 & 0.0032 & 1193.8 & 0.73 \\
\hline
\end{tabular}


The writer is indebted to Prof. R. A. Fisher for the following method of obtaining $\rho_{\mathrm{A}}$ from $\rho_{\mathrm{A}}$ and $\rho_{\mathrm{Cl}}$.

$$
\text { Let } \Lambda \pm \rho_{\mathrm{A}}=\frac{\mathrm{A} \pm \rho_{\mathrm{A}}}{\mathrm{Cl} \pm \rho_{\mathrm{Cl}}}=\frac{\mathrm{A}\left(1 \pm \xi_{\mathrm{A}}\right)}{\mathrm{Cl}\left(1 \pm \xi_{\mathrm{Cl}}\right)}
$$

Then since, for small variations, the relative variance of the quotient is equal to the sum of the relative variances of the numerator and denominator,

$$
\begin{aligned}
& \therefore \quad \Lambda \pm \rho_{\Lambda}=\frac{\mathrm{A}}{\mathrm{Cl}}\left(1 \pm \sqrt{\xi_{\mathrm{A}}^{2}+\xi_{\mathrm{Cl}}^{2}}\right) \\
& \therefore \quad \rho_{\mathrm{A}}=\frac{\mathrm{A}}{\mathrm{Cl}} \sqrt{\xi_{\mathrm{A}}^{2}+\xi_{\mathrm{Cl}}^{2}}
\end{aligned}
$$

In Table I are first given date, station, depth and the excess base in milliequivalents per litre, $A_{v}$, for comparison with earlier work. Then follow excess base in milliequivalents per kilogram, $A_{w}$, and chlorinity in grams per kilogram each with their standard error and the number of sub-samples. Finally is given the specific alkalinity, $\Lambda_{w} \times 10^{4}$.

Since the mean values and their standard errors are to be used for further statistical calculations, they are given to five significant figures. Although this is not usual in chemical work it is felt that the tests of significance in Table II are thereby rendered more precise.

\section{TABLE II.}

\section{Variation of Specific Alkalinity with Depth.}

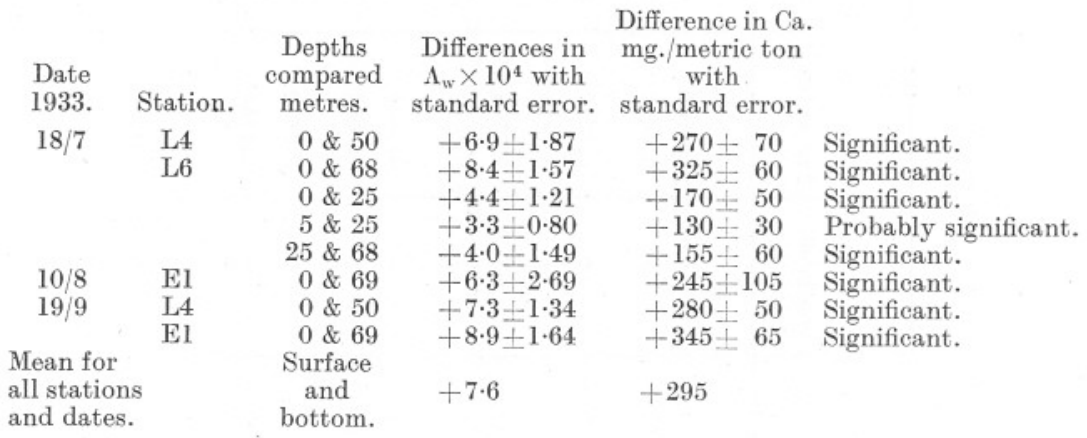

It will be seen that in all cases the specific alkalinity increases with depth. In Table II will be found the differences in specific alkalinity, $\Lambda_{\mathrm{w}} \times 10^{4}$, between given pairs of depths. The standard error of the difference is derived from the expression :-

$$
\rho_{\Delta \text { diff. }}=\sqrt{\rho_{\Delta_{1}}{ }^{2}+\rho_{\Lambda_{2}}{ }^{2}}
$$


These differences are all positive, that is, the specific alkalinity increased with depth. They are somewhat less than was found in 1931, but owing to the groups of analyses being made each on sub-samples of one sample the standard errors are much less.

There remains little doubt that the variations found in 1931 were real and that small variations in specific alkalinity do occur in the shallow waters of the English Channel.

As a result of Wattenberg's investigations (5) on board the Meteor in the South Atlantic, it would appear that these variations are in large part due to variations in calcium. According to his data the water in the English Channel is always slightly supersaturated with calcium carbonate (Table III). Since in summer the percentage supersaturation amounts to

\section{TABLE III.}

Percentage Saturation of Calcium as Carbonate within the Range of pH and Temperature found in the English Channel, (from data by Wattenberg, 5, Table 31).

$\begin{array}{rrrrr}\mathrm{pH} & 8 \cdot 0 & 8 \cdot 1 & 8 \cdot 2 & 8 \cdot 3 \\ \mathrm{t},{ }^{\circ} \mathrm{C} . & 110 & 115 & 121 & 128 \\ 8^{\circ} & 113 & 119 & 126 & 134 \\ 12^{\circ} & 117 & 124 & 132 & 140 \\ 16^{\circ} & & \end{array}$

30 or 40 per cent, the increase in calcium towards the bottom cannot be attributed to re-solution of bottom deposits ; rather must the water be regarded as in unstable equilibrium ready to deposit calcium carbonate on suitable nuclei of calcite (cf. Wattenberg's review of the literature of this subject, 5).

The lower calcium content of the surface water can be explained by deposition of calcium carbonate in the skeletons of flagellates and calcareous algæ which afterwards die off, falling to the bottom, or are eaten, the calcium going to build up the skeletons of crustaceans and teleosts (see however p. 753).

The presence of calcium and other cations as chlorides in body fluids in concentrations similar to those in sea-water does not affect these calculations. In the main, depletion of calcium in the water may be attributed to its deposition as carbonate or phosphate in the skeletons. Magnesium, in so far as it is concerned in such deposition, is included with calcium for the purposes of this discussion.

The degree of accuracy necessary for the statistical treatment is relative and confined within any one batch of samples analysed at any one time. Analyses made at different times are affected by errors in the 
standardisation of the baryta by hydrochloric acid, of the hydrochloric acid by sodium carbonate and of any change in the latter standard. These have not been treated statistically. Thus summer determinations of specific alkalinity could not be compared in time with spring determinations even if these existed.

Nevertheless the data of July 18th, 1933, for Station L6 may be used for a very rough calculation of the production of calcareous plankton.

Let us suppose that the bottom layer of water (68 metres) had remained unchanged in its specific alkalinity, $\Lambda_{w}$, since the previous winter. The differences in $\Lambda_{\mathrm{w}}$ between this layer and the surface, 5 -metre, and 25-metre layers are known (Table II), so that with the aid of the procedure outlined in (1), p. 723, it is possible to work out the total deficiency in $\Lambda_{\mathrm{w}}$ for the whole water column of 70 metres depth and one sq. metre cross-section.

$$
\delta \Lambda_{\mathrm{w}} \times 10^{4}=\delta \frac{\mathrm{A}_{\mathrm{w}}}{\mathrm{Cl}} \times 10^{4}=212 \cdot 2
$$

Regarding $\mathrm{Cl}$ as constant and equal to $19 \cdot 4 \mathrm{~g}$. per $\mathrm{kg}$. or $19 \cdot 4 \times 10^{3} \mathrm{~g}$. per metric ton,

$\therefore \quad \delta A_{w}=\frac{19 \cdot 4 \times 10^{3}}{10^{4}} \times 212 \cdot 2$ milliequivalents for the whole water column.

For the present purpose the density of the sea-water may be taken as unity, so that $\delta \mathrm{A}_{\mathrm{w}}=\delta \mathrm{A}_{\mathrm{v}}$;

whence $\delta \mathrm{A}_{\mathrm{v}}=410$ milliequivalents for a column 1 sq. metre in crosssection and 70 metres deep.

If the entire loss of excess base can be attributed to deposition of calcium in plant skeletons, this is equivalent to $8.2 \mathrm{~g}$. Ca beneath each sq. metre or 8.2 metric tons beneath each sq. kilometre. The writer has been unable to find any quantitative data on the amount of calcium in the skeletons. of calcareous phytoplankton, but if this is assumed to be $10 \%$ of the wet weight the production of calcareous algæ works out at 82 metric tons per sq. kilometre of surface. This figure may be compared with the total plankton crops calculated from changes in other constituents in (2), p. 744 .

Minimum productio
phytoplankton wet
metric tons per sq
1,600
1,000
$1,400 *$
1,500
110
82

* This figure is corrected from the original (1,200 tons) for the salt error in the determination of phosphate which was ignored. 
As was stated in (2), p. 744, silica is of no use to animals feeding on diatoms and is probably excreted immediately into the sea-water where it may be quickly redissolved. If the intestinal juices of the zooplankton are alkaline it may even be excreted already in solution. In either case, the silica appears to take part in the life cycle several times in one season.

So far as calcium is concerned, the writer is not clear just how far zooplankton, such as, for example, Limacina and the larvæ of other molluscs, are dependent for calcium on their ingested food or how far they are able to absorb it directly from the sea-water across the body wall, but in either case the net result will be its removal from the water for the life of the animal or until the next moult.

Since a part of the calcium consumption may be attributable to direct assimilation by zooplankton without first passing through the stage of phytoplankton, the above calculation is strictly comparable neither with the silicate nor with the first four of the above nutrient salt data.

The writer is greatly indebted to Prof. R. A. Fisher of the Galton Laboratory, to whom the draft of the paper was submitted, for helpful criticism and advice. The following quotations are taken, with permission, from a letter of his dealing with the validity of the statistical treatment.

" . . I think that, with the precautions you mention on page 2 (p. 747 of text), as to randomising the flasks in the laboratory, there can be no question of the validity of your conclusion. Reading to three figures, beginning with 5 is equivalent to admitting errors up to \pm 1 in 1000 , or a standard error of observation of about 0.7 in 1200 . The fact, however, that you have based each value on not less than four subsamples reduces this so to speak deliberate error to a half, or in some cases nearly to a quarter of this value. So that there is no theoretical impossibility in your finding, as you have done, differences of 6 or 8 units definitely significant."

Referring to the reporting of data to five significant figures, he says : " Personally I should like to see the five figures retained, as they make the tests of significance definitely more precise, but if it goes against the grain of chemical tradition to publish final figures, which are very unlikely to be exact for the material examined, it might be made clear that such a figure as 1193.3 with a standard error \pm 0.93 implies that the final figures lie between 1191.4 and 1195.2 with the rather high probability of about 20 to 1 , but as among the numbers within this range the value printed, $1193 \cdot 3$, is only the most likely among a number of values of almost equal plausibility. In fact, if you were giving a guarantee, you would probably not take narrower limits than I have stated. But 1193.3 is definitely, though not greatly, more likely than $1193 \cdot 0$, just as at 68 metres $1201 \cdot 7$ is more likely than $1202 \cdot 0$, so that the test of significance appropriate to the 
comparison of these two most likely values is properly carried out on the difference $8 \cdot 4$, whereas the approximate difference $9 \cdot 0$ would be rather inaccurate for this purpose."

\section{SUMMARY.}

In the English Channel in summer a small difference in specific alkalinity between the surface and bottom waters has been established by a statistical method. This is not due to re-solution of bottom deposits of calcium carbonate with which the water is supersaturated. It is attributed to removal of calcium from the surface waters by plankton and an attempt has been made to calculate the production of calcareous plankton.

\section{REFERENCES.}

1. Cooper, L. H. N. Chemical Constituents of Biological Importance in the English Channel, November, 1930, to January, 1932. Part I. Phosphate, silicate, nitrate, nitrite, ammonia. Journ. Mar. Biol. Assoc., N.S., Vol. XVIII, 1933, pp. 677-728.

2. C Chemical Constituents of Biological Importance in the English Channel, November, 1930, to January, 1932. Part II. Hydrogen ion concentration, excess base, carbon dioxide and oxygen. Ibid., 1933, pp. 729-754.

3. — A System of Rational Units for Reporting Nutrient Salts in SeaWater. Journ. du Conseil International p. l'Exploration de la Mer, Vol. VIII, 1933, pp. 331-334.

4. Wattenberg, H. Über die Bestimmung der Alkalinität des Meerwassers. Über den Kalkgehalt des Ozeanwassers. I Mitteilung. Ann. d. Hydrographie usw., Vol. LVIII, 1930, pp. 277-282.

5. — Über die Titrationsalkalinität und den Kalziumkarbonatgehalt des Meerwassers. Wiss. Ergebnisse, Meteor, Bd. VIII, 1933, pp. 122-231.

6. Zorelt, F. Beiträge zur Kenntnis der Alkalinität des Meerwassers. Ann. d. Hydrographie usw., Vol. LXI, 1933, pp. 18-22. 